\title{
Guidelines for the treatment of central nervous system metastases using radiosurgery
}

\author{
DiRETRIZES PARA TRATAMENTO DE TUMORES METASTÁTICOS DE SISTEMA NERVOSO CENTRAL
} COM RADIOCIRURGIA

\author{
Authorship: Brazilian Society of Radiotherapy (SBRT) \\ Participants: Gustavo Nader Marta ${ }^{1}$, Helena Espindola Baraldi ${ }^{1}$, Fabio Ynoe de Moraes ${ }^{1}$
}

Final draft: June 20, 2017

${ }^{1}$ Sociedade Brasileira de Radioterapia (SBR)

The Guidelines Project, an initiative of the Brazilian Medical Association, aims to combine information from the medical field in order to standardize procedures to assist the reasoning and decision-making of doctors.

The information provided through this project must be assessed and criticized by the physician responsible for the conduct that will be adopted, depending on the conditions and the clinical status of each patient.

\section{Grades of Recommendation AND LEVELS OF EVIDENCE}

- A: Experimental or observational studies of higher consistency.

- B: Experimental or observational studies of lower consistency.

- C: Cases reports (non-controlled studies).

- D: Opinion without critical evaluation, based on consensus, physiological studies or animal models.

\section{Objective}

The purpose of this guideline is to evaluate the radiosurgery technique for the treatment of patients with central nervous system (CNS) metastatic tumors.

\section{DESCRIPTION OF EVIDENCE COLLECTION METHOD}

Through the elaboration of six relevant clinical questions related to the proposed theme, we sought to present the main evidence regarding safety, toxicity and effectiveness of radiosurgery in the treatment of CNS metastases. The study population consisted of male and female patients of all ages, with metastatic CNS cancer independent of histological type and presence or absence of comorbidities. For this, a systematic review of the literature was carried out in primary scientific databases (Medline - PubMed; Embase - Elsevier; Lilacs - Bireme; Cochrane Library - Record of Controlled Trials). All articles available through Thursday, April 2, 2015 were considered. The search strategy used in Medline searches is described in Appendix 1. The articles were selected based on critical evaluation, seeking the best evidence available. The recommendations were elaborated after discussion with the elaboration group composed by three members of the Brazilian Society of Radiotherapy. The guideline was reviewed by an independent group, which specializes in evidence-based clinical guidelines. After completion, the guideline was released for public consultation for 15 days, the suggestions obtained being forwarded to the authors for evaluation and possible insertion in the final text.

\section{INTRODUCTION}

Brain metastases are the most frequent intracranial tumors in the adult population. It is estimated that 6 to $30 \%$ of patients diagnosed with malignant systemic disease will have cerebral metastases at some point in their natural progression..$^{1-3}$

In recent years, the incidence of brain metastasis has been increasing mainly due to the implementation in clinical practice of cranial magnetic resonance imaging (MRI), which has good accuracy in detecting early neoplastic lesions in the CNS. In addition, there was a significant improvement in the control of extracranial disease, something associated with the use of new systemic therapies available for the treatment of several cancers. ${ }^{4-6}$

In the adult population, the primary tumors most frequently related to the development of CNS metastases are lung, melanoma, kidney, breast and colorectal cancer. ${ }^{7}$

Regarding pathogenesis, CNS metastases are most commonly due to hematogenous spread. Metastases are usually located directly at the junction of the gray matter and white matter where the diameter of the blood vessels 
is reduced favoring the clusters of tumor cells; $80 \%$ of metastases appear in the cerebral hemispheres. ${ }^{8}$

Clinical manifestations vary according to the number, volume, and location of CNS metastases. The main symptoms described are headache, nausea, vomiting, focal neurological dysfunction and cognitive dysfunction. ${ }^{9}$

Local treatment for CNS metastases depends primarily on the prognosis of the clinical condition and age of the patient. There are several tools available to aid in the classification of patients with brain metastasis regarding prognostic factors and their possible impact on median survival. These tools may therefore facilitate the decision of the most appropriate local treatment for cancer. ${ }^{10,11}$

For patients considered to have poor prognosis, treatment should be focused on the control of symptoms caused by cerebral metastasis aimed at maintaining neurological functioning and quality of life. For those with good prognosis, local treatment should aim to eradicate and control metastatic CNS disease. In this scenario, the options available are surgical resection and radiotherapy (whole brain radiotherapy or radiosurgery), either alone or combined.

Radiosurgery is a radiotherapy technique that is capable of delivering high doses of radiation at pre-defined small target volumes. It is a complex technique that utilizes multiple treatment fields (coplanar and non-coplanar beam plans) that converge to the desired target(s), allowing adjacent healthy tissues to be significantly spared and treatment to be performed quickly, non-invasively and safely. ${ }^{12}$

\section{WHAT IS THE TOXICITY OF RADIOSURGERY FOR BRAIN METASTASES?}

Toxicity after the use of radiosurgery is generally low. Patients are unlikely to have side effects that negatively impact their quality of life.

Fokas et al. showed levels of acute toxicity grade 3 (headache, nausea and vomiting) as low as 3\% in patients undergoing radiosurgery. Similarly, rates of chronic toxicity grade 3 (alopecia, headache, motor and neurocognitive deficits, visual and auditory deficits) of only $6 \%$ were observed. ${ }^{13}$ (B)

Kim et al. used the Common Terminology Criteria for Adverse Events, version 3.0 to measure the toxicity of 58 patients who underwent radiosurgery for the treatment of CNS metastases. Ten patients had some degree of toxicity identified (five patients with grade 1 toxicity, one patient with grade 2 toxicity, and four patients with grade 3 toxicity). The events observed included headache, vertigo, hemiparesis, visual acuity deficit or cerebral necrosis..$^{14}(\mathbf{B})$

Flickinger et al. demonstrated that only four patients out of 116 evaluated developed perilesional edema with worsening of neurological symptoms requiring the intro- duction of supportive therapy with steroids. Of the entire cohort of patients, intracranial tumor hemorrhage occurred in only three $(2.5 \%)$ patients. ${ }^{15}(\mathbf{B})$

Lim et al. conducted a randomized phase 3 clinical trial with patients diagnosed with non-small cell lung cancer with 1 to 4 brain metastases who underwent radiosurgery followed by chemotherapy, or chemotherapy alone. Treatment with radiosurgery was well tolerated and there was no difference in neurocognitive function between the two study groups. ${ }^{16}(\mathbf{A})$

Even when the tumor is located in critical areas, radiosurgery is feasible. Luther et al. observed that motor function improves by $31 \%$ or remains stable in $50 \%$ of patients with brain metastases located in the motor cortex treated with radiosurgery. ${ }^{17}$ (B) Other authors have evaluated the role of radiosurgery in patients with brainstem metastases. Asymptomatic perilesional edema occurred in $4 \%$, while $2.4 \%$ of the patients developed tumor hemorrhage at the treatment site. ${ }^{18,19}(\mathbf{B})$

\section{Recommendation}

Radiosurgery has low morbidity and is associated with low rates of side effects.

\section{What IS THE MAXIMUM NUMBER AND SIZE OF METASTATIC LESIONS IN THE BRAIN FOR RADIOSURGERY TREATMENT TO BE PERFORMED?}

Empirical doses and volume thresholds were established for single dose radiosurgery in order to minimize the risks of side effects. Existing recommendations define up to four lesions and a maximum diameter of $4 \mathrm{~cm}$ as the ideal group for the indication of primary radiosurgery, or dose boost after whole brain irradiation ${ }^{20-23}$ (A) (Table 1). Nevertheless, there are retrospective series of patients with up to 15 metastatic lesions treated with radiosurgery who had clinical progression, complications and responses similar to those treated with up to four lesions. ${ }^{24,25}$ Some authors suggest that total tumor volume is more important than the absolute number of lesions, ${ }^{26-28}$ but this statement requires further investigation. (B)

\begin{tabular}{|c|c|c|c|}
\hline Study & $\begin{array}{l}\text { Grade of } \\
\text { recommendation }\end{array}$ & $\begin{array}{l}\text { Number } \\
\text { of lesions }\end{array}$ & $\begin{array}{l}\text { Size } \\
\text { (diameter) }\end{array}$ \\
\hline RTOG $90-05^{23}$ & A & 1 & $<4 \mathrm{~cm}$ \\
\hline RTOG 95-08 20 & A & $1-3$ & $3 \mathrm{~cm}$ \\
\hline Kondiziolka ${ }^{21}$ & A & $2-4$ & $\leq 25 \mathrm{~mm}$ \\
\hline Mehta $^{22}$ & A & $3-4$ & $4 \mathrm{~cm}$ \\
\hline
\end{tabular}


Recommendation

Radiosurgery should preferably be performed in patients with up to four lesions and a maximum diameter of $4 \mathrm{~cm}$.

\section{What ARE THE ADVANTAGES OF RADIOSURGerY COMPARED TO WHOLE BRAIN RADIOTHERAPY?}

Radiosurgery has the advantage of offering a more conformed and localized treatment, with larger ablative doses than whole brain radiotherapy. ${ }^{29-32}$

Thus, it minimizes the deleterious effects of whole brain radiotherapy with regard mainly to neurocognitive deficit and declining quality of life..$^{22,30,32-34}(\mathbf{A})$

Another important point is that radiosurgery offers higher rates of local control, even in patients with histologically radioresistant tumors (requiring higher doses of ionizing radiation, e.g., melanoma, renal tumors, and sarcoma) compared with whole brain radiotherapy. ${ }^{35,36}$ (B)

\section{Recommendation}

Radiosurgery decreases the risk of neurocognitive decline and can positively impact the patients' quality of life.

\section{What is the EFFectiveness OF RadIOSURgery IN THE APPROACH OF PATIENTS WITH BRAIN METASTASES?}

Radiosurgery alone for the treatment of brain metastases produces local control rates ranging from 65 to $94 \% .^{15,37,38}(\mathbf{B})$

The main factors related to local control after radiosurgery are: characteristics of tumor lesion and treatment dose. Doses lower than 14 Gy and cystic and necrotic lesions are associated with a greater likelihood of recurrence. ${ }^{39,40}(\mathbf{B})$

The efficacy of radiosurgery does not depend on the histological type of the primary tumor since local control rates are similar in both radiosensitive and radioresistant tumors. $^{41-43}(\mathbf{B})$

\section{Recommendation}

Radiosurgery is effective for the treatment of patients with brain metastases, even in those with histologically radioresistant primary tumors.

\section{What aRe the BENEFITS AND DISADVANTAGES OF PERFORMING TWO TREATMENT MODALITIES INVOLVING RADIOSURGERY AND WHOLE BRAIN RADIOTHERAPY IN PATIENTS WITH BRAIN METASTASES?}

There have been some randomized phase 3 trials evaluating the use of radiosurgery (RS) associated with whole brain radiotherapy (WBRT) or WBRT alone in patients with brain metastases and limited disease (1 to 4 intraparenchymal lesions). ${ }^{20,21}$

Aoyama et al. reported a 12 -month CNS recurrence rate of $46.8 \%$ for the WBRT+RS group and $76.4 \%$ for RS alone $(p<0.001)$, and 73 and $89 \%(p=0.002)$ of local control for the RS and WBRT+RS groups, respectively. However, there was no difference in overall survival between groups. ${ }^{29}$ (A)

Chang et al. reported that patients treated with WBRT+RS have a rate of learning decline and mean functional memory of 52 versus $24 \%$ in the RS group. Although brain metastasis-free survival rates at one year were higher in the WBRT+RS (73\%) than in the RS (23\%) group, there was no difference in overall survival and RS patients were easily rescued with new therapy. ${ }^{30}(\mathbf{A})$

Brown et al. presented data according to which the addition of WBRT to RS, despite improving local control (50.5 $\times 84.9 \%$ at one year with RS alone and WBRT + RS, respectively), did not lead to an increase in overall survival and was negatively correlated with some cognitive decline, especially for memory, verbal fluency and immediate memory in the WBRT+RS group $(\mathrm{p}<0.05) .{ }^{44}(\mathbf{A})$

In a systematic review that included the meta-analysis of individual data from randomized clinical trials, the authors noted that in patients aged less than 50 years, with 1 to 4 lesions and good performance, the use of RS alone led to longer overall survival, whereas the initial omission of WBRT did not produce any more failures in $\mathrm{CNS}^{45}$ (A)

In addition, despite worse local control rates and higher rates of salvage treatment, RS proved in the economic analysis to be more cost effective than WBRT+RS. ${ }^{46}(\mathbf{B})$

\section{Recommendation}

The addition of whole brain radiotherapy in patients treated with radiosurgery allows greater intracranial local control, despite no positive impact on overall survival. The use of whole brain radiotherapy may be related to worsening of cognition, verbal function and memory.

\section{After surgical resection of brain METASTASES, IS THERE A ROLE FOR ADJUVANT RADIOSURGERY IN THE SURGICAL BED?}

In the postsurgical adjuvant scenario, one of the standard treatment regimens is to perform whole brain radiotherapy. ${ }^{47-48}$

However, in order to avoid the detrimental effects of whole brain radiotherapy, some authors advocate the use of adjuvant radiosurgery in the surgical bed.

A phase 2 clinical study evaluated the use of radiosurgery with a median dose of 18 Gy in patients with performance status $\geq 70$ and $\leq 2$ resected brain metastases. Local and regional failure rates of 22 and 44\%, 
respectively, were demonstrated at 12 months. There was more benefit for lesions $<3 \mathrm{~cm}$ and deep. ${ }^{49}$ (B) Several other studies with patients treated similarly showed local control rates of approximately 75 to $90 \%$ and 60 to $80 \%$ after one and two years of follow-up, respectively. These results are comparable with the local control achieved in patients who received postoperative whole brain radiotherapy. ${ }^{50-54}(\mathbf{B})$

Moreover, postoperative radiosurgery improves local control compared with observation alone for completely resected brain metastases. Data from a randomized phase 3 trial demonstrated that local control rates are statistically significant higher in patients who received radiosurgery (local control rates in 6 months and 12 months were $83 \%, 57 \%$ and $72 \%, 45 \%$, for radiosurgery and observation groups, respectively). ${ }^{55}$ (A)

Recently, two important studies were presented in ASCO and ASTRO. Kayama et al. conduced a non-inferiority phase 3 trial (JCOG0504) to assess the effectiveness of radiosurgery for residual and recurrent brain metastases after surgical resection. Patients were randomized to receive radiosurgery or whole brain radiotherapy. The overall survival rates were similar in both groups. ${ }^{56}(\mathbf{A})$ Similarly, Brown et al. randomized patients with 1 to 4 brain metastases to either whole brain radiotherapy or radiosurgery after surgical resection. More cognitive deterioration was observed in whole brain radiotherapy group. No differences in overall survival were demonstrated between the groups and better quality of life was reported in the radiosurgery arm. ${ }^{57}(\mathbf{A})$

\section{Recommendation}

After surgery, adjuvant radiosurgery may be employed to replace whole brain radiotherapy.

\section{ApPendix 1}

\section{Search strategy - MEDLINE}

(Central Nervous System [Mesh] OR Central Nervous Systems OR Nervous System, Central OR Nervous Systems, Central OR System, Central Nervous OR Systems, Central Nervous) AND (Neoplasm Metastasis [Mesh] OR Metastases, Neoplasm OR Neoplasm Metastases OR Metastasis OR Metastases OR Metastasis, Neoplasm) AND (Radiosurgery [Mesh] OR Radiosurgeries OR Radiosurgery, Stereotactic OR Radiosurgeries, Stereotactic OR Stereotactic Radiosurgeries OR Stereotactic Radiosurgery OR Gamma Knife Radiosurgery OR Gamma Knife Radiosurgeries OR Radiosurgeries, Gamma Knife OR Radiosurgery, Gamma Knife OR Stereotactic Body Radiotherapy OR Body Radiotherapies, Stereotactic OR
Body Radiotherapy, Stereotactic OR Radiotherapies, Stereotactic Body OR Radiotherapy, Stereotactic Body OR Stereotactic Body Radiotherapies OR CyberKnife Radiosurgery OR CyberKnife Radiosurgeries OR Radiosurgeries, CyberKnife OR Radiosurgery, CyberKnife OR Radiosurgery, Linear Accelerator OR Linear Accelerator Radiosurgeries OR Radiosurgeries, Linear Accelerator OR Linear Accelerator Radiosurgery OR Radiosurgery, Linac OR Radiosurgeries, Linac OR LINAC Radiosurgery OR Radiosurgeries, LINAC)

\section{Conflict of interest}

The authors declare no conflict of interest.

\section{REFERENCES}

1. Johnson JD, Young B. Demographics of brain metastasis. Neurosurg Clin N Am. 1996; 7(3):337-44.

2. Wen PY, Loeffler JS. Management of brain metastases. Oncology (Williston Park). 1999; 13(7):941-54, 57-61; discussion 61-2, 9

3. Graus F, Walker RW, Allen JC. Brain metastases in children. J Pediatr. 1983; 103(4):558-61.

4. Paterson AH, Agarwal M, Lees A, Hanson J, Szafran O. Brain metastases in breast cancer patients receiving adjuvant chemotherapy. Cancer. 1982; 49(4):651-4.

5. Sundermeyer ML, Meropol NJ, Rogatko A, Wang H, Cohen SJ. Changing patterns of bone and brain metastases in patients with colorectal cancer. Clin Colorectal Cancer. 2005; 5(2):108-13.

6. Davis PC, Hudgins PA, Peterman SB, Hoffman JC Jr. Diagnosis of cerebral metastases: double-dose delayed CT vs contrast-enhanced MR imaging. AJNR Am J Neuroradiol. 1991; 12(2):293-300.

7. Barnholtz-Sloan JS, Sloan AE, Davis FG, Vigneau FD, Lai P, Sawaya RE. Incidence proportions of brain metastases in patients diagnosed (1973 to 2001) in the Metropolitan Detroit Cancer Surveillance System. J Clin Oncol. 2004; 22(14):2865-72.

8. Delattre JY, Krol G, Thaler HT, Posner JB. Distribution of brain metastases. Arch Neurol. 1988; 45(7):741-4.

9. Clouston PD, DeAngelis LM, Posner JB. The spectrum of neurological disease in patients with systemic cancer. Ann Neurol. 1992; 31(3):268-73.

10. Gaspar L, Scott C, Rotman M, Asbell S, Phillips T, Wasserman T, et al. Recursive partitioning analysis (RPA) of prognostic factors in three Radiation Therapy Oncology Group (RTOG) brain metastases trials. Int J Radiat Oncol Biol Phys. 1997; 37(4):745-51.

11. Weltman E, Salvajoli JV, Brandt RA, de Morais Hanriot R, Prisco FE, Cruz JC, et al. Radiosurgery for brain metastases: a score index for predicting prognosis. Int J Radiat Oncol Biol Phys. 2000; 46(5):1155-61.

12. Barnett GH, Linskey ME, Adler JR, Cozzens JW, Friedman WA, Heilbrun MP, et al.; American Association of Neurological Surgeons; Congress of Neurological Surgeons Washington Committee Stereotactic Radiosurgery Task Force. Stereotactic radiosurgery - an organized neurosurgery-sanctioned definition. J Neurosurg. 2007; 106(1):1-5.

13. Fokas E, Henzel M, Surber G, Kleinert G, Hamm K, Engenhart-Cabillic R. Stereotactic radiosurgery and fractionated stereotactic radiotherapy: comparison of efficacy and toxicity in 260 patients with brain metastases. J Neurooncol. 2012; 109(1):91-8.

14. Kim YJ, Cho KH, Kim JY, Lim YK, Min HS, Lee SH, et al. Single-dose versus fractionated stereotactic radiotherapy for brain metastases. Int J Radiat Oncol Biol Phys. 2011; 81(2):483-9.

15. Flickinger JC, Kondziolka D, Lunsford LD, Coffey RJ, Goodman ML, Shaw EG, et al. A multi-institutional experience with stereotactic radiosurgery for solitary brain metastasis. Int J Radiat Oncol Biol Phys. 1994; 28(4):797-802.

16. Lim SH, Lee JY, Lee MY, Kim HS, Lee J, Sun JM, et al. A randomized phase III trial of stereotactic radiosurgery (SRS) versus observation for patients with asymptomatic cerebral oligo-metastases in non-small-cell lung cancer. Ann Oncol. 2015; 26(4):762-8. 
17. Luther N, Kondziolka D, Kano H, Mousavi SH, Flickinger JC, Lunsford LD. Motor function after stereotactic radiosurgery for brain metastases in the region of the motor cortex. J Neurosurg. 2013; 119(3):683-8.

18. Şengöz M, Kabalay IA, Tezcanlı E, Peker S, Pamir N. Treatment of brainstem metastases with gamma-knife radiosurgery. J Neurooncol. 2013; 113(1):33-8.

19. Peterson HE, Larson EW, Fairbanks RK, MacKay AR, Lamoreaux WT, Call JA, et al. Gamma knife treatment of brainstem metastases. Int J Mol Sci. 2014; 15(6):9748-61.

20. Andrews DW, Scott CB, Sperduto PW, Flanders AE, Gaspar LE, Schell MC, et al. Whole brain radiation therapy with or without stereotactic radiosurgery boost for patients with one to three brain metastases: phase III results of the RTOG 9508 randomised trial. Lancet. 2004; 363(9422):1665-72.

21. Kondziolka D, Patel A, Lunsford LD, Kassam A, Flickinger JC. Stereotactic radiosurgery plus whole brain radiotherapy versus radiotherapy alone for patients with multiple brain metastases. Int J Radiat Oncol Biol Phys. 1999; 45(2):427-34.

22. Mehta MP, Tsao MN, Whelan TJ, Morris DE, Hayman JA, Flickinger JC, et al. The American Society for Therapeutic Radiology and Oncology (ASTRO) evidence-based review of the role of radiosurgery for brain metastases. Int J Radiat Oncol Biol Phys. 2005; 63(1):37-46.

23. Shaw E, Scott C, Souhami L, Dinapoli R, Kline R, Loeffler J, et al. Single dose radiosurgical treatment of recurrent previously irradiated primary brain tumors and brain metastases: final report of RTOG protocol 90-05. Int J Radiat Oncol Biol Phys. 2000; 47(2):291-8.

24. Knisely JP, Yamamoto M, Gross CP, Castrucci WA, Jokura H, Chiang VL. Radiosurgery alone for 5 or more brain metastases: expert opinion survey. J Neurosurg. 2010; 113 Suppl:84-9.

25. Rava P, Leonard K, Sioshansi S, Curran B, Wazer DE, Cosgrove GR, et al. Survival among patients with 10 or more brain metastases treated with stereotactic radiosurgery. J Neurosurg. 2013; 119(2):457-62.

26. Bhatnagar AK, Flickinger JC, Kondziolka D, Lunsford LD. Stereotactic radiosurgery for four or more intracranial metastases. Int J Radiat Oncol Biol Phys. 2006; 64(3):898-903.

27. Skeie BS, Skeie GO, Enger PØ, Ganz JC, Heggdal JI, Ystevik B, et al. Gamma knife surgery in brain melanomas: absence of extracranial metastases and tumor volume strongest indicators of prolonged survival. World Neurosurg. 2011; 75(5-6):684-91; discussion 598-603.

28. Xue J, Kubicek GJ, Grimm J, LaCouture T, Chen Y, Goldman HW, et al. Biological implications of whole brain radiotherapy versus stereotactic radiosurgery of multiple brain metastases. J Neurosurg. 2014; 121 Suppl:60-8.

29. Aoyama H, Shirato H, Tago M, Nakagawa K, Toyoda T, Hatano K, et al. Stereotactic radiosurgery plus whole brain radiation therapy vs stereotactic radiosurgery alone for treatment of brain metastases: a randomized controlled trial. JAMA. 2006; 295(21):2483-91.

30. Chang EL, Wefel JS, Hess KR, Allen PK, Lang FF, Kornguth DG, et al. Neurocognition in patients with brain metastases treated with radiosurgery or radiosurgery plus whole brain irradiation: a randomised controlled trial. Lancet Oncol. 2009; 10(11):1037-44.

31. Tsao M, Xu W, Sahgal A. A meta-analysis evaluating stereotactic radiosurgery, whole brain radiotherapy, or both for patients presenting with a limited number of brain metastases. Cancer. 2012; 118(9):2486-93.

32. Soffietti R, Kocher M, Abacioglu UM, Villa S, Fauchon F, Baumert BG, et al. A European Organisation for Research and Treatment of Cancer phase III trial of adjuvant whole brain radiotherapy versus observation in patients with one to three brain metastases from solid tumors after surgical resection or radiosurgery: quality-of-life results. J Clin Oncol. 2013; 31(1):65-72.

33. Sun A, Bae K, Gore EM, Movsas B, Wong SJ, Meyers CA, et al. Phase III trial of prophylactic cranial irradiation compared with observation in patients with locally advanced non-small-cell lung cancer: neurocognitive and qualityof-life analysis. J Clin Oncol. 2011; 29(3):279-86.

34. Gondi V, Paulus R, Bruner DW, Meyers CA, Gore EM, Wolfson A, et al. Decline in tested and self-reported cognitive functioning after prophylactic cranial irradiation for lung cancer: pooled secondary analysis of Radiation Therapy Oncology Group randomized trials 0212 and 0214. Int J Radiat Oncol Biol Phys. 2013; 86(4):656-64.

35. Meyners T, Heisterkamp C, Kueter JD, Veninga T, Stalpers LJ, Schild SE, et al. Prognostic factors for outcomes after whole brain irradiation of brain metastases from relatively radioresistant tumors: a retrospective analysis. BMC Cancer. 2010; 10:582.

36. Seastone DJ, Elson P, Garcia JA, Chao ST, Suh JH, Angelov L, et al. Clinical outcome of stereotactic radiosurgery for central nervous system metastases from renal cell carcinoma. Clin Genitourin Cancer. 2014; 12(2):111-6.
37. Alexander E 3rd, Moriarty TM, Davis RB, Wen PY, Fine HA, Black PM, et al. Stereotactic radiosurgery for the definitive, noninvasive treatment of brain metastases. J Natl Cancer Inst. 1995; 87(1):34-40.

38. Pirzkall A, Debus J, Lohr F, Fuss M, Rhein B, Engenhart-Cabillic R, et al. Radiosurgery alone or in combination with whole brain radiotherapy for brain metastases. J Clin Oncol. 1998; 16(11):3563-9.

39. Schomas DA, Roeske JC, MacDonald RL, Sweeney PJ, Mehta N, Mundt AJ. Predictors of tumor control in patients treated with linac-based stereotactic radiosurgery for metastatic disease to the brain. Am J Clin Oncol. 2005; 28(2):180-7.

40. Rodrigues G, Zindler J, Warner A, Lagerwaard F. Recursive partitioning analysis for the prediction of stereotactic radiosurgery brain metastases lesion control. Oncologist. 2013; 18(3):330-5.

41. Shuto T, Inomori S, Fujino H, Nagano H. Gamma knife surgery for metastatic brain tumors from renal cell carcinoma. J Neurosurg. 2006; 105(4):555-60.

42. Auchter RM, Lamond JP, Alexander E, Buatti JM, Chappell R, Friedman WA et al. A multiinstitutional outcome and prognostic factor analysis of radiosurgery for resectable single brain metastasis. Int J Radiat Oncol Biol Phys. 1996; 35(1):27-35.

43. Wowra B, Siebels M, Muacevic A, Kreth FW, Mack A, Hofstetter A. Repeated gamma knife surgery for multiple brain metastases from renal cell carcinoma. J Neurosurg. 2002; 97(4):785-93

44. Brown PD, Asher AL, Ballman KV, Farace E, Cerhan JH, et al. NCCTG N0574 (Alliance): a phase III randomized trial of whole brain radiation therapy (WBRT) in addition to radiosurgery (SRS) in patients with 1 to 3 brain metastases. J Clin Oncol. 2015; 33(15 suppl; abstr LBA4).

45. Sahgal A, Aoyama H, Kocher M, Neupane B, Collette S, Tago M, et al. Phase 3 trials of stereotactic radiosurgery with or without whole brain radiation therapy for 1 to 4 brain metastases: individual patient data meta-analysis. Int J Radiat Oncol Biol Phys. 2015; 91(4):710-7.

46. Hall MD, McGee JL, McGee MC, Hall KA, Neils DM, Klopfenstein JD, et al. Cost-effectiveness of stereotactic radiosurgery with and without whole brain radiotherapy for the treatment of newly diagnosed brain metastases. J Neurosurg. 2014; 121 Suppl:84-90.

47. Patchell RA, Tibbs PA, Walsh JW, Dempsey RJ, Maruyama Y, Kryscio RJ, et al. A randomized trial of surgery in the treatment of single metastases to the brain. N Engl J Med. 1990; 322(8):494-500.

48. Noordijk EM, Vecht CJ, Haaxma-Reiche H, Padberg GW, Voormolen JH, Hoekstra FH, et al. The choice of treatment of single brain metastasis should be based on extracranial tumor activity and age. Int J Radiat Oncol Biol Phys. 1994; 29(4):711-7.

49. Brennan C, Yang TJ, Hilden P, Zhang Z, Chan K, Yamada Y, et al. A phase 2 trial of stereotactic radiosurgery boost after surgical resection for brain metastases. Int J Radiat Oncol Biol Phys. 2014; 88(1):130-6.

50. Mathieu D, Kondziolka D, Flickinger JC, Fortin D, Kenny B, Michaud K, et al. Tumor bed radiosurgery after resection of cerebral metastases. Neurosurgery. 2008; 62(4):817-23; discussion 823-4.

51. Hartford AC, Paravati AJ, Spire WJ, Li Z, Jarvis LA, Fadul CE, et al. Postoperative stereotactic radiosurgery without whole brain radiation therapy for brain metastases: potential role of preoperative tumor size. Int J Radiat Oncol Biol Phys. 2013; 85(3):650-5.

52. Do L, Pezner R, Radany E, Liu A, Staud C, Badie B. Resection followed by stereotactic radiosurgery to resection cavity for intracranial metastases. Int J Radiat Oncol Biol Phys. 2009; 73(2):486-91.

53. Soltys SG, Adler JR, Lipani JD, Jackson PS, Choi CY, Puataweepong P, et al. Stereotactic radiosurgery of the postoperative resection cavity for brain metastases. Int J Radiat Oncol Biol Phys. 2008; 70(1):187-93.

54. Minniti G, Esposito V, Clarke E, Scaringi C, Lanzetta G, Salvati M, et al. Multidose stereotactic radiosurgery ( 9 Gy x 3 ) of the postoperative resection cavity for treatment of large brain metastases. Int J Radiat Oncol Biol Phys. 2013; 86(4):623-9.

55. Rao G, Ahmed S, Hess K, Mahajan A. Postoperative Stereotactic Radiosurgery vs Observation for Completely Resected Brain Metastases: Results of a Prospective Randomized Study. Neurosurgery. 2016; 63 Suppl 1:184.

56. Kayama T, Sato S, Sakurada K, Mizusawa J, Nishikawa R, Narita Y et al. JCOG0504: A phase III randomized trial of surgery with whole brain radiation therapy versus surgery with salvage stereotactic radiosurgery in patients with 1 to 4 brain metastases. Available on: http://meetinglibrary.asco.org/ record/125226/abstract.

57. Brown PD, Ballman KV, Cerhan J, Anderson SK, Carrero XW, Whitton AC et al. N107C/CEC.3: A Phase III Trial of Post-Operative Stereotactic Radiosurgery (SRS) Compared with Whole Brain Radiotherapy (WBRT) for Resected Metastatic Brain Disease. Int J Radiat Oncol Biol Phys. 2016; 96(5):937. 